Proceedings of the 11th Polish-Japanese Joint Seminar on Micro and Nano Analysis, Gniew, September 11-14, 2016

\title{
Formability Evaluation of Aluminium Alloys by FLD Diagrams
}

\author{
P. Petroušek ${ }^{a, *}$, R. KoČIŠKo ${ }^{a}$, T. KvaČKaJ ${ }^{a}$, R. BidulskÝ ${ }^{a}$, J. Bidulská ${ }^{a}$, \\ A. FEDORIKOVÁ ${ }^{a}$ AND P. SABOL ${ }^{b}$ \\ ${ }^{a}$ Institute of Materials,Faculty of Metallurgy, Technical University of Košice, Letná 9, 04200 Košice, Slovakia \\ ${ }^{b}$ Department of Concrete and Mansory Structures, Institute of Structural Engineering, Faculty of Civil Engineering, \\ Technical University of Košice, Vysokoškolská 4, 04200 Košice, Slovakia
}

\begin{abstract}
The goal of the present work is evaluated mechanical properties and forming limit diagrams of ambient rolled aluminium alloy based on AlMgSi. Forming limit diagrams are convenient and often used as a tool for the classification of the formability and the evaluation of the forming process of sheet materials. Forming limits of sheet metal are represented in the forming limit diagrams occurring by various deformation states. The most widely used type is the Keeler-Goodwin diagram. Input data got from static tensile test are important for formability evaluating of the thin sheet by mathematical simulations, such as tensile strength, yield strength, elongation, and the strain hardening exponent. The result is a consideration of the suitability of the material for stamping technology.
\end{abstract}

DOI: 10.12693/APhysPolA.131.1344

PACS/topics: 81.20.Hy, 62.10.+s, 62.20.M-, 81.05.-t, 82.80.--d

\section{Introduction}

Aluminum $\mathrm{Al}-\mathrm{Mg}-\mathrm{Si}$ systems are age-hardened alloys with precipitates $\langle\mathrm{Mg}$; Si $\rangle$ which are used in many industries, especially in the automobile one $[1,2]$. These alloys are used for forming automotive parts. AlMgSi alloys are announced as EN AW 6000 series alloys. Mg and $\mathrm{Si}$ are the major content in these alloys, which increase the strength of the material by the formation of strengthening agents (precursors to $\mathrm{Mg}_{2} \mathrm{Si}$ ) during the paint-bake cycle. Mg increases the strength, hardenability, and corrosion resistance. Si increases the strength of the solid solution and also to a lesser extent the corrosion resistance. Alloys intended for forming have a quantity of $\mathrm{Mg}<8 \%$ and $\mathrm{Si}<1 \%$ [3-7]. Heat-treatable AlMgSi alloys are considered as the most promising candidates for high-strength automotive body panels due to their high strength-to-weight ratio, good formability, and resistance to corrosion. These alloys display a significant increase in hardness during the heat treatment. Heat-treatment is important for a formation of large numbers of nanosized semicoherent metastable precipitates that slow down dislocation movement in the host material [8-12].

The forming limit diagram (FLD) as an essential tool is applied to predict the onset of necking in sheet metal forming operations. Limit strains are the maximum strains which were in sheet metals before the onset of necking. The FLD is a plot of the forming limit strains in the space of principal (in-plane) strains. In the discussion that follows major and minor limit strains refer to the maximum and minimum values of the in-plane princi-

*corresponding author; e-mail: patrik.petrousek@tuke.sk pal limit strains, respectively [13]. The major limit strain is usually represented by the vertical axis and the minor strain by the horizontal axis [14]. For creating FLD diagram we can use two different approaches. The first method is manually applying a grid to the surface of the sample which is defining the various changes in the dimensions of the elements. The second method currently most used lies in the application of contrasting points on the surface of the sample. This surface is scanned using high-resolution cameras and the image is evaluated in the software that operates on the principle DIC method [15-17].

In this paper there are obtained mechanical properties and microhardness of aluminium alloy. Formability of aluminium alloy can be characterized by FLD diagrams. FLD diagrams may be formed by a DIC method in ARAMIS software. For monitoring deformation in a real time there was used the videoextensometric system by Horizon Videoextensometer.

\section{Experimental procedures}

As experimental material there were used EN AW 6000 series aluminium alloys based AlMgSi, both in a T4 heat treatment state according to DIN EN 515. Experimental material was cold rolled to a thickness of $2 \mathrm{~mm}$. The static tensile test was conducted by standard STN EN ISO 6892-1 on the tensile test machine. In the static tensile test static conditions were used and speed of equipment movement was $0.13 \mathrm{~mm} / \mathrm{s}$. A chemical composition of aluminium alloys is shown in Table I.

The samples were prepared in three different directions towards the rolling direction $\left(0^{\circ}, 45^{\circ}, 90^{\circ}\right)$ - Fig. 1. Mechanical properties were evaluated by tensile test - yield strength (YS), ultimate tensile strength (UTS), elongation $\left(A_{80}\right)$ and strain hardening index $(n)$. To obtain deformation maps from which FLD diagrams were created 
TABLE I

The local chemical analysis [mass\%].

\begin{tabular}{c|c|c|c|c|c|c|c}
\hline \hline Material & $\mathrm{Si}$ & $\mathrm{Fe}$ & $\mathrm{Cu}$ & $\mathrm{Mn}$ & $\mathrm{Mg}$ & $\mathrm{Cr}$ & $\mathrm{Al}$ \\
\hline $\mathrm{A}$ & 1.24 & 0.214 & 0.072 & 0.126 & 0.347 & 0.026 & 97.8 \\
\hline $\mathrm{B}$ & 0.87 & 0.189 & 0.138 & 0.155 & 0.571 & 0.008 & 97.7
\end{tabular}

it was necessary to create a special type of the samples, which were published at work [6].

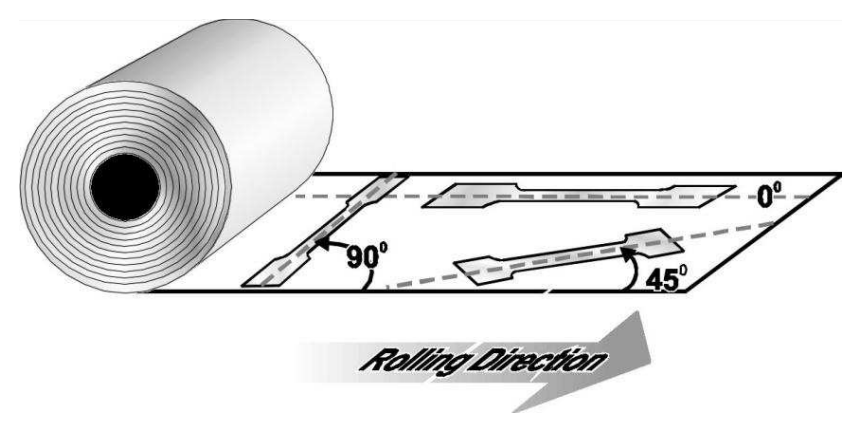

Fig. 1. Schematic showing the three principal directions in a rolled plate for determining anisotropy.

\section{Results and discussion}

Figure 2 is a diagram of the ultimate tensile strength and the yield strength for both types of materials. The mechanical properties were measured in three different rolling directions $0^{\circ}, 45^{\circ}$ and $90^{\circ}$. The graph shows that samples with a higher silicon content reached lower values of mechanical properties. The differences in elongation were not as pronounced. They differ by about $3 \%$. The differences of mechanical properties in different rolling directions are minimal. The samples taken in the rolling direction exhibited about $15 \mathrm{MPa}$ higher of strength properties, and the elongation was the same. Higher content of $\mathrm{Cu}$ in material B increases the mechanical properties. This results in a finding that the samples taken in the rolling direction are most suitable for the stamping processes, irrespective of the chemical composition.

Figure 3 shows a plot of elongation and the strain hardening exponent according to the direction of rolling. The strain hardening exponent was determined from $5 \%$ strain according to ISO 10275:2007. Based on the picture it can be stated that the elongation was approximately the same in all samples. According to Zhong et al. the values of the strain hardening exponent are almost the same at different ratios of $\mathrm{Mg}: \mathrm{Si}$. This is confirmed by the measurement with the result that the ratio of $\mathrm{Mg}$ :Si does not have a uniform effect on the course of deformation.

Microhardness was monitored in mentioned ways to the rolling directions. The result that the rolling direction does not have effect on microhardness, is confirmed by the box plot (Fig. 4). Microhardness between the alloys varied by $\Delta 15 \mathrm{HV}$.

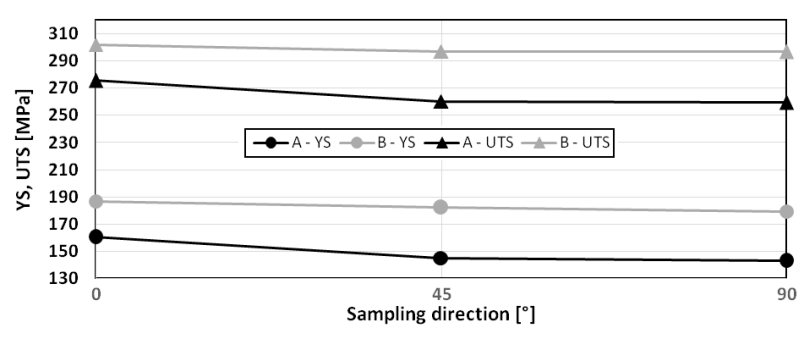

Fig. 2. A comparison of the yield strength (YS) and ultimate tensile strength (UTS).

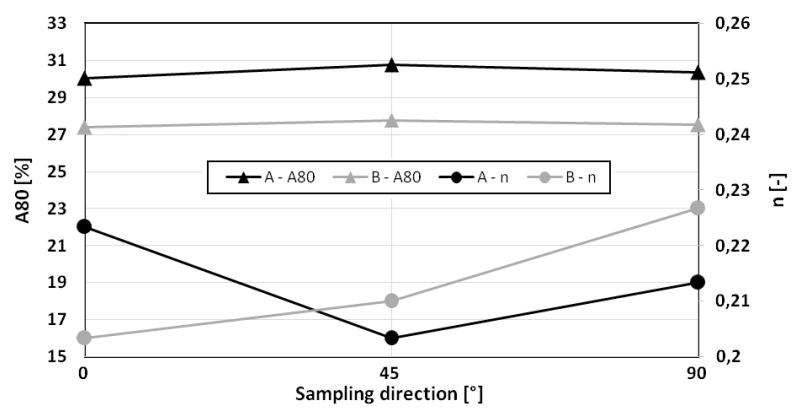

Fig. 3. A comparison of exponent strain hardening a ductility.

In Fig. 5 deformation maps made by Aramis software for 5 different radii of curvature are shown. As seen with increasing radius is the maximum deformation concentrated into the center of the sample. The smallest radius of curvature (R5) was the maximum deformation of the material $\mathrm{A}-33 \%$ and material $\mathrm{B}-25 \%$. On the radius, $R_{40}$ was the maximum deformation for materials A - $71 \%$ and for material B - 57\%. From the comparison of the two materials is seen that the material A has a greater crack resistance.

Based on the deformation maps, FLD diagram can be created for both materials (Fig. 6). The area above incurred curves gives us the values that are at risk for making cracking. Points are limits before disrupting the samples in a tensile test. The position of these points is greatly influenced by the speed of the movement of tensile machine and thickness of the material. These parameters are the same, so we can conclude that the difference in the

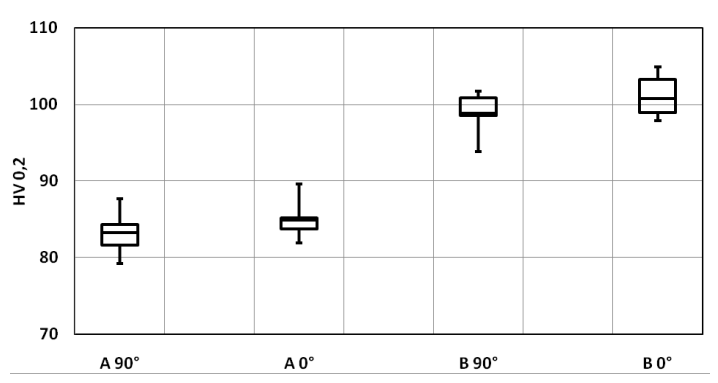

Fig. 4. A comparison of microhardness. 


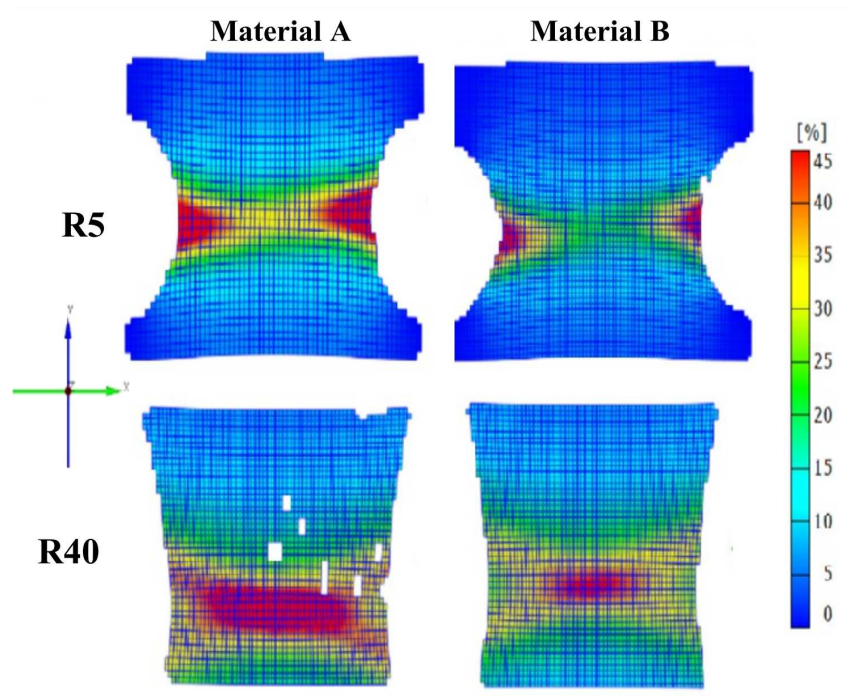

Fig. 5. The deformation maps for different radii of specimens.

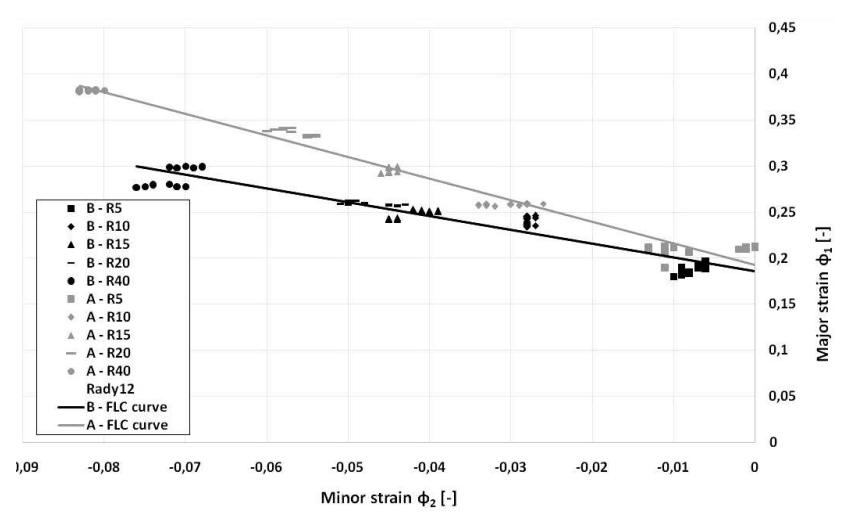

Fig. 6. Left side of FLD diagram.

position of the curve is due to the chemical composition and especially ratio of Si:Mg. This difference increases with increasing curvature radius of the samples. FLD diagram has a function to highlight the risk of cracking.

\section{Conclusions}

In the present study mechanical properties of aluminium alloys based AlMgSi are compared. According to this study, the following conclusions can be made:

- The effect of the rolling direction has very little effect on the mechanical properties of these alloys.

- Significant effects on the mechanical properties has the ratio of Si:Mg, where can be seen that with increasing ratio mechanical properties are decreasing.
- The resulting FLD diagram for stamping processes is more suitable for alloy "A", because it has a greater safety area.

\section{Acknowledgments}

This work was realized within the frame of the Operational Program Research and Development: "The centre of competence for industrial research and development in the field of light metals and composites", project code ITMS: 26220220154.

\section{References}

[1] W.S. Miller, L. Zhuang, J. Bottema, A.J. Wittebrood, P. De Smet, A. Haszler, A. Vieregge, Mater. Sci. Eng. A 280, 37 (2000).

[2] J. Hirsch, Mater. Trans. 52, 818 (2011).

[3] A. Esmaeili, X. Wang, D.J. Lloyd, W.J. Poole, Metall. Mater. Trans. A Phys. Metall. Mater. Sci. 34, 751 (2003).

[4] T. Kvackaj, J. Bidulska, M. Fujda, R. Kocisko, I. Pokorny, O. Milkovic, Mater. Sci. Forum 633-634, 273 (2010).

[5] J. Bidulská, T. Kvackaj, R. Bidulský, M. Actis Grande, Acta Phys. Pol. A 122, 553 (2012).

[6] P. Petroušek, T. Kvačkaj, R. Kočiško, R. Bidulský, J. Bidulská, A. Fedoriková, T. Hlava, Acta Metall. Slov. 21, 176 (2015).

[7] C.D. Marioara, S.J. Andersen, T.N. Stene, H. Hasting, J. Walmsley, A.T.J. Van Helvoort, R. Holmestad, Philos. Mag. 87, 3385 (2007).

[8] J. Bidulska, T. Kvackaj, R. Bidulsky, M.A. Grande, Kov. Mater. 46, 339 (2008).

[9] M.A. van Huis, J.H. Chen, H.W. Zandbergen, M.H.F. Sluiter, Acta Mater. 54, 2945 (2006).

[10] G. Svenningsen, M.H. Larsen, J.H. Nordlien, K. Nisancioglu, Corrosion Sci. 48, 258 (2006).

[11] J.Y. Chang, A. Shan, Mater. Sci. Eng. A Struct. Mater. Prop. 347, 165 (2003).

[12] R. Kočiško, R. Bidulský, L. Dragošek, M. Škrobian, Acta Metall. Slov. 20, 302 (2014).

[13] K. Kolasangiani, M. Shariati, K. Farhangdoost, J. Comput. Appl. Res. Mech. Eng. 4, 121 (2015).

[14] A. Graf, W. Hosford, Int. J. Mech. Sci. 36, 897 (1994).

[15] H. Zhong, P.A. Rometsch, L.F. Cao, Y. Estrin, Mater. Sci. Eng. A Struct. Mater. Prop. Microstruct. Process. 65, 688 (2016).

[16] A.R. Carr, A. Walker, E. Combaz, Int. J. Mater. Form. 8, 45 (2015).

[17] Z.F. Zhang, Y.L. Kang, H.W. Wang, Q.H. Qin, Y. Qiu, X.Q. Li, Measurement 39, 710 (2006). 